\title{
METABOLIT SEKUNDER DARI BATANG PHYSALIS PERUVIANA (SOLANACEAE)
}

\author{
L. Rosmainar \\ Progam Studi Farmasi, Politeknik Meta Industri Cikarang \\ Email: lilisr@politeknikmeta.ac.id
}

\begin{abstract}
ABSTRAK
Penelitian ini dilakukan terhadap tanaman Physalis peruviana yang telah banyak dimanfaatkan dalam pengobatan tradisional. Tujuan penelitian ini adalah untuk mengisolasi senyawa metabolit sekunder dari batang tanaman Physalis peruviana dan menentukan strukturnya. Senyawa-senyawa yang banyak ditemukan dalam genus Physalis adalah steroid, seperti yang terdapat dalam P. angulata, P. philadelpica, P. alkekengi, dan P. virginiana. Metode yang digunakan adalah dengan maserasi menggunakan metanol kemudian diekstraksi dengan menggunakan n-heksan dan etil asetat, dan selanjutnya dilakukan pemisahan senyawa dengan menggunakan teknik kromatografi. Hasil penelitian menunjukkan bahwa senyawa yang didapat memiliki titik leleh $195^{\circ}$ - $196^{\circ} \mathrm{C}$ dengan massa 0,20 gram yang berbentuk serbuk berwarna putih. Penentuan struktur dilakukan dengan FTIR (3269 $\left.\mathrm{cm}^{-1}, 2924 \mathrm{~cm}^{-1}, 1678 \mathrm{~cm}^{-1}\right)$, MS (m/z 485,2552), NMR ID $\left({ }^{1} H-N M R ~ \&{ }^{13} C-N M R\right)$, NMR 2D (HMBC, HMQC, COSY) serta membandingkan hasil spektra dengan senyawa yang telah diperoleh sebelumnya. Senyawa yang diperoleh merupakan golongan senyawa Witasteroid dan struktur yang disarankan adalah $4 \beta$-Hidroksiwithanolida $E$.
\end{abstract}

Kata kunci: $4 \beta$-hidroksiwithanolide E, P. peruviana, Solanaceae, steroid, witasteroid.

\section{ABSTRACT}

The object of this research was Physalis peruviana plants that have been widely used in traditional medicine. This study aimed to isolate the secondary metabolite compounds from Physalis peruviana stems and determine their structure. The compounds commonly found in the genus of Physalis are steroids, such as found in P. angulata, P. philadelpica, P. alkekengi, and P. virginiana. The method used was maceration with methanol and then extraction by using $n$-hexane and ethyl acetate, followed by separation of the compound by using chromatography. The results showed that the compound obtained has a melting point of $195^{0}-196^{\circ} \mathrm{C}$ with a mass of 0.20 gram in the form of white powder. Structural determination was performed with FTIR $\left(3269 \mathrm{~cm}^{-1}\right.$, $2924 \mathrm{~cm}^{-1}, 1678 \mathrm{~cm}^{-1}$ ), MS (m/z 485,2552), NMR 1D (1H-NMR \& 13C-NMR), NMR 2D (HMBC, HMQC, COSY) as well as comparing the spectral results with previously established compounds. The compound obtained is a class of Withasteroid compounds and the recommended structure is $4 \beta$-Hydroxywithanolida E.

Keywords: $4 \beta$-hidroksiwithanolide E; peruviana; Solanaceae; steroid; withasteroid.

\section{PENDAHULUAN}

Indonesia merupakan salah satu negara tropis yang terkenal memiliki keanekaragaman baik hayati maupun non hayati, salah satu kekayaan hayati yaitu tumbuhan yang tersebar luas di seluruh Indonesia dengan berbagai macam kegunaan misalnya sebagai tanaman obat. Salah satu tanaman obat yang sering digunakan masyarakat adalah Physalis peruviana. $P$. peruviana termasuk dalam keluarga Solanaceae, dan merupakan tanaman yang banyak tumbuh liar di kebun atau tanah kosong yang kondisinya sedikit basah. Tanaman ini telah dimanfaatkan dalam pengobatan tradisional seperti mengobati diabetes, gusi berdarah, bisul, maag dan menurunkan panas (Siyok, 2002). Physalis dapat tumbuh hampir di seluruh wilayah Indonesia. Masing-masing daerah memberi nama yang berbeda-beda, berdasarkan daerah asal masing-masing, seperti : Cecendet (sunda), Ceplukan (Jawa Tengah), Jorjoran (Madura), Ciciplukan (Bali), Dedes (Sasak), Leletopan (Makasar), Lapununat (Seram), Pultak-Pultak (Medan). Sementara Houzuki (Jepang), Morel berry (Inggris), sedangkan Winter cherry (Cina) (Vessal, dkk., 1991).

Tanaman ini tersebar luas di seluruh dunia baik daerah tropis maupun subtropis seperti Afrika, Asia, Mexico, Amerika Tengah dan Amerika Selatan (David dkk., 2005). Di Indonesia, seperti di Jawa, tanaman ini tumbuh secara liar di kebun, tegalan, tepi jalan, kebun, semak, dan tepi hutan. Tanaman ini termasuk tanaman semak/perdu sehingga dapat 
mengganggu lahan (Siyok, 2002). Senyawasenyawa aktif yang terkandung dalam $P$. peruviana antara lain steroid, alkaloid, flavonoid, dan saponin (Hall \& Vernon, 2004). Kandungan kimia dalam herba $P$. peruviana

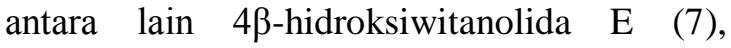
witanolida E (8), witaperuvin (9) (Damu, 2007 \& Lan, 2009), piperunolida B (10), piperunolida C (11), piperunolida D (12), witapisanolida, pisalakton, witaperuvin D (Lan, 2009). Sejak lama, physalis telah diteliti oleh para ahli dari berbagai negara. Penelitian tersebut biasanya terfokus pada aktivitas yang dimilikinya. Dari penelitian yang telah dilakukan, baik secara in vitro maupun in vivo, diketahui bahwa $P$. peruviana dapat mengobati berbagai penyakit seperti antimikroba, antitumor, antiperadangan dan antibakteri (Lan, dkk., 2009). Dalam penelitian ini akan dilakukan isolasi metabolit sekunder turunan steroid dari batang $P$. peruviana.

\section{MATERI DAN METODE \\ Bahan}

Tumbuhan $P$. peruviana yang diperoleh dari desa Palalangon, kecamatan Ujung Berung, Jawa Barat di daerah gunung Palasari.

Bahan kimia yang digunakan yaitu pelarut organik seperti kloroform, etil asetat, $n$-heksan, metanol, aseton, silica gel Si gel Merck 60 (35-70 mesh), Si gel Merck 60 $\mathrm{GF}_{254}$, dan Si gel Merck $60 \mathrm{PF}_{254}$.

\section{Peralatan}

Alat yang digunakan adalah gelas kimia, gelas ukur, erlenmeyer, batang pengaduk, spatula, pipit tetes, chamber, corong buchner, kromatografi lapis tipis, kromatografi kolom gravitasi, kromatografi vakum cair, kromatografi radial (kromatotron), rotary evaporator, neraca timbang, dan seperangkat alat destilasi.

Untuk analisis struktur digunakan spektroskopi UV-Vis, IR menggunakan alat spektrometer Shimadzu FTIR 8501 dan NMR menggunakan alat JEOL ECA 500, yang bekerja pada $500 \mathrm{MHz}\left({ }^{1} \mathrm{H}\right)$ dan $125 \mathrm{MHz}$ $\left({ }^{13} \mathrm{C}\right)$.

\section{CARA KERJA \\ Preparasi}

Bagian batang tanaman Physalis peruviana diambil dan dipisahkan lalu dikeringkan. Bagian batang yang telah kering diambil dan digiling hingga menjadi serbuk halus.

\section{Ekstraksi}

Proses ekstraksi dilakukan dengan metode padat-cair (maserasi) dan cair-cair. Pada proses ekstraksi padat-cair (maserasi) digunakan pelarut metanol yang secara umum merupakan pelarut yang baik untuk melarutkan semua senyawa yang ada didalam tanaman $P$. peruviana. Proses ekstraksi padatcair (maserasi) diulang sebanyak 3 kali dengan penggantian pelarut selama 1 x 24 jam. Kemudian dilakukan proses dekantasi dengan menggunakan $\mathrm{MeOH}: \mathrm{H}_{2} \mathrm{O}=1$ : 2 dan dimasukkan dalam wadah tertutup selama 24 jam. Hasil dekantasi tersebut kemudian dilanjutkan dengan proses ekstraksi cair-cair dengan menggunakan pelarut $n$-heksan yang diulang sebanyak 3 kali dan etil asetat yang diulang sebanyak 5 kali.

\section{Isolasi}

Proses isolasi senyawa metabolit sekunder dari tanaman ini dilakukan dengan menggunakan kromatografi vakum cair, kromatografi kolom tekan, kromatografi gravitasi dan kromatografi radial.

\section{Skrining Fitokimia Terpenoid dan Steroid Tak Jenuh.}

Uji kualitatif dilakukan dengan menggunakan pereaksi Lieberman-Buchard yaitu dengan menambahkan anhidrida asetat dan asam sulfat pekat ke dalam sampel. Uji kualitatif ini bertujuan untuk mendeteksi keberadaan senyawa steroid atau terpenoid. Hasil positif untuk senyawa terpenoid ditandai munculnya warna merah. Uji positif untuk senyawa steroid ditandai dengan munculnya warna biru hingga hijau.

\section{Skrining Fitokimia Flavonoid}

Uji kualitatif dilakukan dengan menggunakan pereaksi Wilstater yaitu dengan menambahkan $\mathrm{HCl}$ pekat dan pita logam $\mathrm{Mg}$ kedalam sampel. Adanya flanvonoid ditandai dengan warna merah, orange, dan hijau tergantung pada jenis flavonoid yang terkandung.

\section{Skrining Fitokimia Alkaloid}

Uji kualitatif ini dilakukan dengan menggunakan pereaksi Meyer, Dragendorf dan 
Wagner. Sampel yang dilarutkan dalam kloroform beramonia disaring kemudian filtrat diambil dan ditambahkan dengan asam sulfat $2 \mathrm{~N}$ dan dikocok sehingga membentuk 2 lapisan. Kemudian lapisan atas diambil dan diuji dengan pereaksi Meyer, Dragendrof, dan Wagner. Pada pereaksi Meyer terbentuknya endapan putih dan endapan coklat kemerahan pada pereaksi Dragendorf dan Wagner menunjukkan adanya alkaloid.

\section{Uji Titik Leleh}

Uji titik leleh merupakan salah satu cara untuk mengidentifikasi kemurnian senyawa yang berbentuk padatan. Senyawa dikatakan murni jika interval titik lelehnya kecil. Hasil uji titik leleh dibandingkan dengan literatur yang ada dari senyawa-senyawa yang terkandung pada tanaman $P$. peruviana.

\section{HASIL DAN PEMBAHASAN}

Serbuk batang $P$. peruviana sebanyak $1,6 \mathrm{~kg}$ diekstraksi dengan ekstraksi padat-cair dengan menggunakan metanol dan kemudian diuapkan menggunakan rotary evaporator sehingga diperoleh ekstrak sebanyak 114,35 g berupa gel yang berwarna hijau kehitaman. Kemudian dilarutkan dalam metanol : $\mathrm{H}_{2} \mathrm{O}$ (1 : 2$)$.

Pada tahap selanjutnya dilakukan ekstraksi cair-cair dengan menggunakan pelarut $n$-heksan sebanyak 3 kali sehingga diperoleh fasa air dan fasa organik. Fasa air diambil dan kemudian diekstraksi kembali dengan menggunakan pelarut etil asetat sebanyak 5 kali sehingga diperoleh kembali fasa air dan fasa organik. Fasa organik diambil dan diuapkan dengan rotary evaporator sehingga diperoleh ekstrak etil asetat sebanyak $22,07 \mathrm{~g}$

Ekstrak etil asetat diambil sebanyak 7 g, kemudian dilakukan pemisahan dengan kromatografi vakum cair dengan peningkatan kepolaran menggunakan pelarut $n$-Heksan : EtOAc : $\mathrm{MeOH}$ dan kemudian difraksinasi menggunakan kromatografi kolom gravitasi dengan perbandingan pelarut $n$-heksan : etil asetat $=2: 8$ dan $100 \%$ etil asetat, lalu difraksinasi menggunakan kromatografi kolom gravitasi menggunakan perbandingan pelarut kloroform : metanol $=17: 1 ; 15: 1 ; 10: 1$.

Kemudian difraksinasi kembali menggunakan kromatografi radial menggunakan per- bandingan pelarut $n$-heksan $:$ etil asetat $=9: 1$ dan etil asetat $100 \%$.

Pada pemisahan dengan menggunakan kromatotron ini, didapat fraksi D memiliki 1 spot noda baik dengan menggunakan penampak noda serium sulfat maupun di bawah sinar UV dan dilanjutkan dengan penentuan struktur dari senyawa tersebut dengan menggunakan spektroskopi NMR.

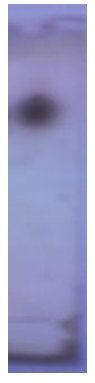

(a)



(b)



(c)
Gambar 1. Hasil KLT

Dimana:
(a) Heksan : Aseton $(3: 10)$
(b) Kloroform : Aseton $(16: 10)$
(c) Etil Asetat (100\%)

\section{Analisis Senyawa}

Pada uji kualitatif menggunakan skrining fitokimia menunjukkan bahwa $P$. peruviana mengandung steroid.

Senyawa yang telah diperoleh berupa padatan berwarna putih. Pada pengujian titik leleh untuk senyawa yang telah diperoleh adalah $195^{\circ}-196^{\circ} \mathrm{C}$. Hal ini menunjukkan kemurnian senyawa yang telah diperoleh karena rentang dari titik leleh yang diperoleh hanya $1^{\circ} \mathrm{C}$.

Tabel 1. Hasil Uji Fitokimia

\begin{tabular}{cccc}
\hline No & $\begin{array}{c}\text { Kandungan } \\
\text { Kimia }\end{array}$ & Pereaksi & Hasil \\
\hline 1 & Alkaloid & $\begin{array}{c}\text { Dragendorf, Meyer, } \\
\text { Wagner }\end{array}$ & - \\
& Flavonoid & HCl pekat + Logam & + \\
2 & Mg & \\
3 & Triterpenoi & Liberman-Buchard & + \\
4 & d & Liberman-Buchard & ++++ \\
& Steroid & \\
\hline \multicolumn{4}{c}{ Ket: + sedikit; ++++ relatif besar) }
\end{tabular}

\section{Data Spektroskopi}


Pada penelitian ini telah berhasil diisolasi satu senyawa metabolit sekunder dari batang $P$. peruviana yaitu $4 \beta$ Hidroksiwithanolida E. Senyawa yang diperoleh berupa padatan berwarna putih sebanyak 0,20 g. Hal ini didukung oleh data FTIR, MS, ${ }^{1} \mathrm{H}-\mathrm{NMR},{ }^{13} \mathrm{C}-\mathrm{NMR}$, DEPT, HMBC, HMQC, dan COSY.

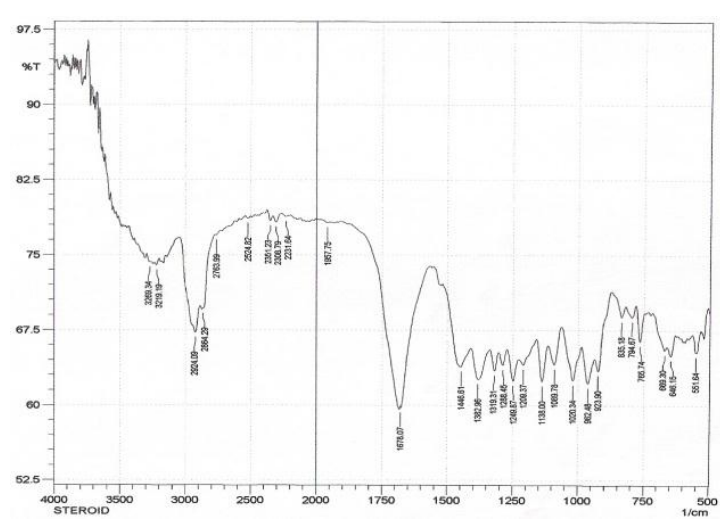

Gambar 2. Spektrum IR

Pada spektrum FTIR terdapat puncak dengan bilangan gelombang $3269 \mathrm{~cm}^{-1}$ menunjukkan adanya serapan ulur -OH, 2924 $\mathrm{cm}^{-1}$ menunjukkan adanya serapan ulur $\mathrm{C}-\mathrm{H}$ alifatik, dan $1678 \mathrm{~cm}^{-1}$ menunjukkan adanya karbonil.

Hasil pengukuran MS menunjukkan nilai $\mathrm{m} / \mathrm{z}$ sebesar 485,2552 , sesuai dengan rumus molekul $\mathrm{C}_{28} \mathrm{H}_{37} \mathrm{O}_{7}$ yang didapat dari fragmentasi $\mathrm{C}_{28} \mathrm{H}_{39} \mathrm{O}_{8}-\mathrm{H}_{2} \mathrm{O}$, hal ini sesuai dengan rumus struktur $\mathrm{C}_{28} \mathrm{H}_{38} \mathrm{O}_{8}$ yaitu senyawa $4 \beta$-Hidroksiwithanolida $\mathrm{E}$ dengan nilai $\mathrm{DBE}=$ 10.

Senyawa ini larut dalam aseton dan kloroform. Hasil data spektroskopi ${ }^{1} \mathrm{H}-\mathrm{NMR}$ memberikan 5 sinyal metil pada nilai geseran kimia $\delta_{\mathrm{H}}=1,07(3 \mathrm{H}) ; 1,41(6 \mathrm{H}) ; 1,87(3 \mathrm{H})$; $1,93(3 \mathrm{H})$. Terdapat 2 proton yang menunjukkan $\alpha, \beta$-unsaturated olefinic pada geseran kimia $\delta_{\mathrm{H}} 6,22(1 \mathrm{H}, \mathrm{d}, \mathrm{J}=9,75 \mathrm{~Hz}, \mathrm{H}-2$ ) dan $6,91\left(1 \mathrm{H}, \mathrm{dd}, \mathrm{J}_{1}=9,75 ; \mathrm{J}_{2}=5,8 \mathrm{~Hz}, \mathrm{H}-3\right)$ (Gambar 3). Nilai kopling untuk satu atom $\mathrm{H}$ di daerah geseran kimia tersebut menunjukkan bahwa masing-masing atom $\mathrm{H}$ tersebut memiliki atom $\mathrm{H}$ tetangga yang menyebabkan kopling secara cis- (konstanta kopling kecil = $9,75 \mathrm{~Hz}$ ). Geseran kimia $\delta_{\mathrm{H}} 6,22$ berada pada posisi $\mathrm{H}-2$ karena proton lebih shielding sedangkan pada geseran kimia $\delta_{\mathrm{H}} 6,91$ berada pada posisi H-3 karena proton lebih deshielding.

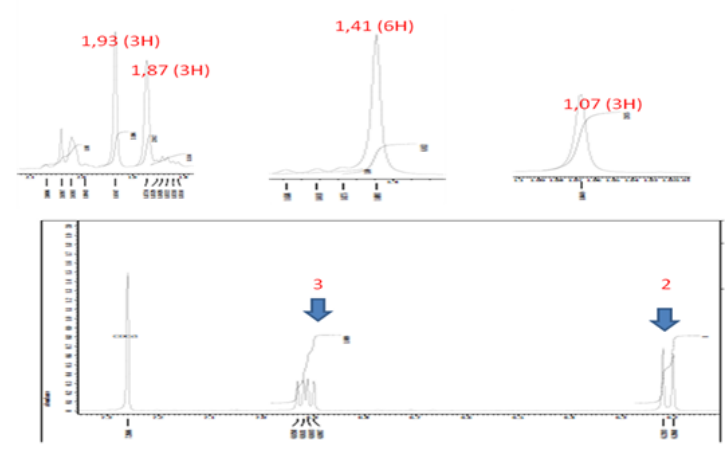

Gambar 3. Spektrum ${ }^{1} \mathrm{H}$ NMR $\left(\mathrm{CDCl}_{3}, 500\right.$ $\mathrm{MHz}$ )

Pada spektrum COSY, H-3 berhubungan dengan $\mathrm{H}-2$ dan $3,73(1 \mathrm{H}, \mathrm{d}, \mathrm{J}=5,8 \mathrm{~Hz}, \mathrm{H}-4)$, merupakan proton yang terikat pada karbon yang terikat oksigen yaitu terikat pada gugus hidoksi (Gambar 3). Data ini menunjukkan struktur 4 $\beta$-hidroksi-2-ena-1-on dalam molekul. Sinyal $\delta_{\mathrm{H}}=3,28(1 \mathrm{H}, \mathrm{s}, \mathrm{H}-6)$ bersama dengan sinyal karbon kuarterner yang terikat oksigen $(\delta 64,2 ;$ C-5) dan karbon oksimetin $(\delta 63,1 ; \mathrm{C}-6)$ menunjukkan $5 \beta, 6 \beta$ epoksi.

Pada spektrum ${ }^{13} \mathrm{C}-\mathrm{NMR}$ (terlampir) dan DEPT (terlampir), senyawa ini menunjukkan adanya jumlah karbon sebanyak $28\left(\mathrm{CH}_{3}=5, \mathrm{CH}_{2}=6, \mathrm{CH}=7, \mathrm{Cq}=10\right)$, yaitu: $\alpha, \beta$-unsaturated keton $(\delta 201,9=\mathrm{C}-1 ; 133,3=$ $\mathrm{C}-2 ; 141=\mathrm{C}-3), \alpha, \beta$-unsaturated $\delta$-lakton $(\delta$ $150,8=\mathrm{C}-24 ; 121,6=\mathrm{C}-25 ; 166=\mathrm{C}-26), 2$ metin yang terikat oksigen $(\delta 70,4=\mathrm{C}-4 ; 79,6$ $=\mathrm{C}-22)$, epoksida $(\delta 64,2=\mathrm{C}-5 ; 63,1=\mathrm{C}-6)$, 3 karbon kuarterner yang terikat oksigen $(\delta$ $81,9=\mathrm{C}-14 ; 87,8=\mathrm{C}-17 ; 79,2=\mathrm{C}-20), 5$ metil $(\delta 20,4=\mathrm{C}-18 ; 16,1=\mathrm{C}-19 ; 19,8=\mathrm{C}-$ $21 ; 12,5=\mathrm{C}-27 ; 20,8=\mathrm{C}-28 ; 6$ metilen $(\delta$ $26,03=\mathrm{C}-7 ; 21,57=\mathrm{C}-11 ; 29,83=\mathrm{C}-12$; $38,05=\mathrm{C}-15 ; 32,52=\mathrm{C}-16 ; 34,45=\mathrm{C}-23), 2$ metin $(\delta 34,3=\mathrm{C}-8 ; 36,8=\mathrm{C}-9)$, dan 2 karbon kuarterner $(\delta$ 47,9 $=\mathrm{C}-10 ; 54,6=\mathrm{C}$ 13). 


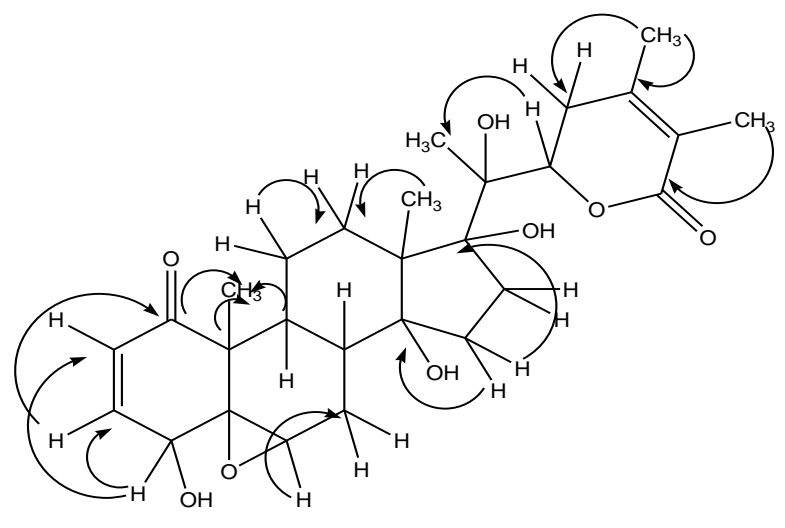

Gambar 4. Korelasi HMBC dari senyawa 4 $\beta$ hidroksiwitanolida $\mathrm{E}$

Untuk memperkuat asumsi bahwa senyawa yang diisolasi adalah $4 \beta$-hidroksiwitanolida $E$, maka data spektrum data isolat dibandingkan dengan data spektrum dari literatur witangulatin $\mathrm{B}$ yang hanya mempunyai perbedaan struktur pada C-15 jika dibandingkan dengan senyawa yang diperoleh, dimana pada witangulatin B karbon-15 terikat pada gugus hidroksi sedangkan pada senyawa yang telah diisolasi C-15 hanya karbon metilen.Berdasarkan data spektroskopi di atas, maka dapat dirangkai struktur senyawa $4 \beta$ Hidroksiwitanolida E, seperti yang diperlihatkan pada Gambar 5.

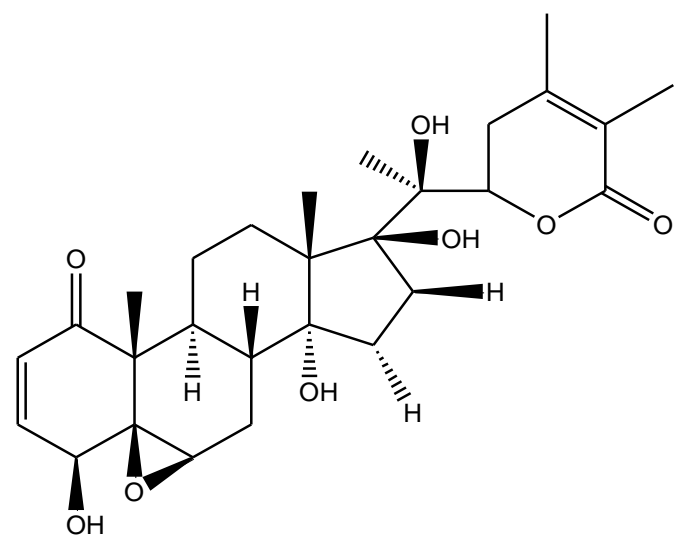

Gambar 5 Struktur 4ßHidroksiwitanolida E

Data ${ }^{13} \mathrm{C}-\mathrm{NMR}$ dan ${ }^{1} \mathrm{H}-\mathrm{NMR}$ yang telah diperoleh untuk senyawa yang telah diisolasi kemudian dibandingkan dengan geseran kimia senyawa Witangulatin B yang mempunyai struktur yang mirip dengan senyawa yang telah diperoleh, dimana perbedaannya hanya pada C-15. Pada Witangulatin B, C-15 terikat 156 pada gugus $-\mathrm{OH}$ sedangkan pada struktur senyawa yang telah diperoleh $\mathrm{C}-15$ hanya berupa metilen. Oleh karena itu, dilakukan perbandingan data yang telah diperoleh terhadap data senyawa yang mempunyai kemiripan struktur dengan senyawa tersebut, seperti terlihat pada Tabel 2.

Tabel 2. Perbandingan data NMR dari Witangulatin B (1) dan 4 $\beta$-Hidroksiwitanolida E

\begin{tabular}{|c|c|c|c|c|}
\hline \multirow{2}{*}{ No } & \multicolumn{2}{|r|}{ Literatur (Witangulatin B) } & \multicolumn{2}{|c|}{ 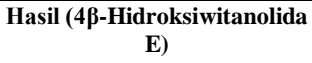 } \\
\hline & $\begin{array}{l}{ }^{13} \mathrm{C}- \\
\text { NMR }\end{array}$ & ${ }^{1}$ H-NMR & $\begin{array}{l}{ }^{13} \mathrm{C}- \\
\text { NMR }\end{array}$ & ${ }^{1} \mathrm{H}-\mathrm{NMR}$ \\
\hline 1 & 201,6 & - & 201,9 & - \\
\hline 2 & 133,0 & $6,22 \mathrm{~d}(10)$ & 133,3 & $6,21 \mathrm{~d}(9,75)$ \\
\hline 3 & 141,2 & $6,91 \mathrm{dd}(10 ; 6)$ & 141,4 & $6,91 \mathrm{dd}(9,75 ; 5,85)$ \\
\hline 4 & 70,3 & 3,73 dd $(6 ; 2,5)$ & 70,4 & $3,73 \mathrm{~d}(5,8)$ \\
\hline 5 & 64,0 & - & 64,2 & - \\
\hline 6 & 62,9 & 3,28 br s & 63,1 & $3,27 \mathrm{~s}$ \\
\hline 7 & 29,6 & $2,25 \mathrm{~m} ; 1,25 \mathrm{~m}$ & 26,0 & $2,02 \mathrm{~m}$ \\
\hline 8 & 32,3 & $1,98 \mathrm{~m}$ & 34,3 & $1,83 \mathrm{~m}$ \\
\hline 9 & 36,6 & $2,75 \mathrm{~m}$ & 36,8 & $1,71 \mathrm{~m}$ \\
\hline 10 & 47,7 & - & 47,9 & - \\
\hline 11 & 21,4 & $1,73 \mathrm{~m} ; 1,53 \mathrm{~m}$ & 21,5 & $1,76 \mathrm{~m}$ \\
\hline 12 & 34,1 & $2,25 \mathrm{~m} ; 1,75 \mathrm{~m}$ & 29,8 & $2,25 \mathrm{~m} ; 1,25 \mathrm{~m}$ \\
\hline 13 & 54,5 & - & 54,6 & - \\
\hline 14 & 81,7 & - & 81,9 & - \\
\hline 15 & 77,4 & $4,88 \mathrm{~d}(5,7)$ & 38,0 & $1,45 \mathrm{~m} ; 1,40 \mathrm{~m}$ \\
\hline 16 & 37,9 & $2,77 \mathrm{dd}(15 ; 6,7) ; 2,63 \mathrm{dd}(15 ; 3,2)$ & 32,5 & $1,66 \mathrm{~m} ; 1,55 \mathrm{~m}$ \\
\hline 17 & 87,6 & - & 87,7 & - \\
\hline 18 & 19,6 & $1,07 \mathrm{~s}$ & 20,4 & $1,06 \mathrm{~s}$ \\
\hline 19 & 16,7 & $1,29 \mathrm{~s}$ & 16,9 & $1,41 \mathrm{~s}$ \\
\hline 20 & 79,0 & - & 79,2 & - \\
\hline 21 & 20,6 & $1,41 \mathrm{~s}$ & 19,8 & $1,41 \mathrm{~s}$ \\
\hline 22 & 79,4 & 4,86 dd $(11 ; 5,2)$ & 79,6 & 4,86 dd $(11,7 ; 5,2)$ \\
\hline 23 & 34,3 & $2,52 \mathrm{~m}$ & 34,4 & $2,50 \mathrm{~m}$ \\
\hline 24 & 150,5 & - & 150,8 & - \\
\hline 25 & 121,4 & - & 121,6 & - \\
\hline 26 & 165,7 & - & 166,0 & - \\
\hline 27 & 12,3 & $1,88 \mathrm{~s}$ & 12,5 & $1,87 \mathrm{~s}$ \\
\hline 28 & 20,6 & $1,94 \mathrm{~s}$ & 20,8 & $1,93 \mathrm{~s}$ \\
\hline
\end{tabular}

\section{SIMPULAN}

\section{Simpulan}

Skrining Fitokimia yang telah dilakukan menunjukkan bahwa fraksi etil asetat mengandung steroid. Penentuan struktur dengan menggunakan spektroskopi IR, MS, dan NMR menunjukkan bahwa senyawa yang telah diisolasi adalah golongan witasteroid yaitu $4 \beta$-Hidroksiwitanolida $E$ yang berbentuk serbuk putih sebanyak $0,2 \mathrm{~g}$ dengan titik leleh $195^{0}-196^{0} \mathrm{C}$. 


\section{UCAPAN TERIMA KASIH}

Penulis mengucapkan terima kasih kepada Dr. Ciptati dan kepada seluruh pihak yang telah membantu proses penelitian ini.

\section{DAFTAR PUSTAKA}

Ahmad, S., Malik, A., Yasmin, R., Ulah, N., Gul, W., Khan, P.M., Nawaz, H.R., Afza, N., 1999, Withanolides from Physalis peruviana, J. Phytochem, 50, 647-651.

Alfinda, N. K., Aminah, N. S., Tanjung, M., Kurniadi, B., 2008, Fitokimia, Universitas Air Langga, 10.

Damu, G.A., Ping-Chung, K., Chung-Ren, S., Tsung-Hsiao, K., Tzu-Hsuan, C., Kenneth, F. B., Kuo-Hsiung, L., and Tian-Shung, W., 2007, Isolation, Structures, and Structure-Cytotoxic Activity Relationships of Withanolides and Physalins from Physalis angulata, J. Nat. Prod., 70, 1146-1152.

David, G.I., James, T., Felicia, E., Timothy, E., Paul, D., 2005, Isolation and characterization of bioactive compounds from Suriname and Madagascar flora, Dissertation submitted to the faculty of the Virginia Polytechnic Institute and State University in partial fulfillment of the requirement for the degree of Doctor of Philosophy In Chemistry, 58-74.

Glotter, E., 1991, Withanolides and related ergostane type steroids, Faculty of Agriculture, The Hebrew University of Jerusalem, 76- 100.

Glotter, E., 1994, Withanolides and related ergostane type steroids, Nat. Prod., $8,415$.

Hall D.W. \& Vernon V.V., 2004, Cutleaf Ground-cherry, Physalis angulata, http://www.edis.ifas.ufl.edu/pdffiles/ FW/FW03100.pdf, diakses tanggal 1 September 2011.

Harborne J.B., 1987, Metode Fitokimia, Bandung, Institut Teknologi Bandung.

Helvaci, G., Kokdil, M., Kawai, N., Duran, G., Duran, and A., Guvenc, 2010,
Antimicrobial activity of the extracts and physalin $D$ from Physalis alkekengi and evaluation of antioxidant potential of physalin $D$, Pharm. Bio, 48, 142-150.

http://anaknetral.blogspot.com/p/rubrik.html, diakses tanggal 7 Oktober 2011.

http://kambing.ui.ac.id/bebas/v12/artikel/ttg_ta naman_obat/depkes/buku3/3-105. pdf, diakses tanggal 19 septermber 2011.

http://www.missouriplants.com/Yellowalt/Phy salis_angulata_page.html, diakses tanggal 7 Oktober 2011.

Januario, A.H., Filho, E.R., Pietro, R.C.L.R., Kashima, S., Sato, D.N., Franca, S.C., 2002, Phytother, Res., 16, 445-448.

Kuo, P.C., 2006, Physanolide A, a novel Skeleton Steroid, and Other Cytotoxic Principles from Physalis angulata, Org. Lett, 8, 2953-2956.

Kirson, I., \& Glotter, E., 1981, Recent developmekts in saterally occurring ergostane-type steroids. A review, Nat. Prod, 44, 633-647.

Lan, Y., H., Chang, F., R., Pan, M., J., Wu, C., C., Wu, S., J., Chen, S., L., Wang, S., S., Wu, M., J., Wu, Y., C., 2009, New citotoxic withanolides from Physalis peruviana, Food Chem, 116, 462-469.

Lijuan, S., Jianwen, L., Ping, L., Youjun, Y., Lei, M., Lihong, H., 2011, Immunosuppression effect of Withangulatin A from Physalis angulata via heme oxygenase 1 dependent pathways, Proc. Biochem, 46, 482-488.

Lin, Y.S., Chiang, H.C., Kaw, W.S., Hone, E., Shih, S.J., Won, M.H., Immunomodulatory activity of various fractions derived from Physalis angulata L. Extract, Am. J. Chin Med., 233.

Magalhaes, H.I.F., Veras, M.L., Torres, M.R., Alves, A.P.N.N., Pessoa, O.D.L., Silveira, E.R., Costa-Lotufo, L.V., Moraes, M.O.D., Pessoa, C., 2006, J. Pharm, 58, 235-241.

Maldonado, E., Amador, S., Martinez, M., Castorena, A.L.P., 2010, Virginols $A-C$, three new withanolides from Physalis virginiana, Els, 75, 346-349 
Matsuura, T., Kawai, M., Nakashima, R., Butsugan, Y., 1970, Structures of physalin $A$ and physalin B, 13,14seco-16,24-cyclosteroids from $P$. alkekengi var. Francheti, J. Chem Soc, 664-670.

Mayorga, H., Knapp, H., Winterhalter, P., Duque, C., 2001, Glycosidically bound flavor compounds of cape gooseberry (Physalis peruviana L.), J. Agric. Food Chem, 49, 1904-1908.

Perez-Castorena, A.L., Garcia, M., Martinez, M., Maldonado, E., 2004, Physalins from Physalis solanaceus. Biochem Syst Ecol, 32, 1231-1234.

Riaz, Naheed, 2004, Phytochemical investigation on the chemical constituents of paeonia emodi wall, alysicarpus monolifer linn. and ajuda bracteosa wall, H.E.J. Research Institute of Chemistry/ University of Karachi, 1-258.
Robinson T., 1995, Kandungan Organik Tumbuhan Tingkat Tinggi, Bandung, Institut Teknologi Bandung.

Siyok D., 2002, Morel Berry, Obat Kencing Manis, www.dayakology.com/kr/ind/2002/8 7/kesehatan.htm-9k, diakses tanggal 1 September 2011.

Vessal M., Mehrani HA., Omrani GH. 1991, Effects of an aqueous extract of Physalis alkekengi fruit on estrus cycle, reproduction and uterine creatine kinase BB-isozyme in rats. J. Ethnopharm, 34, 69-78

Vieira, A.T., Pinho, V., Lepsch, L.B., Scavone, C., Ribeiro, I.M., Tomassini, T., Ribeiro-dos-santos, R., Soares, M.B.P., Teixeira, M.M., Souza, D.G., 2005, Br. J. Pharmacol, 146, 244-251.induced Rat Models, Althea Medical Journal, 1 (2): 81-85. 